\title{
A study of complications in case of unicornuate uterus with rudimentary horn
}

\section{Samarina Kamal*, Priyankur Roy}

Department of Obstetrics and Gynecology, Alam Hospital, Ranchi, Jharkhand, India

Received: 07 May 2017

Accepted: 16 May 2017

\section{*Correspondence:}

Dr. Samarina Kamal,

E-mail: drsamrinakamal@gmail.com

Copyright: (c) the author(s), publisher and licensee Medip Academy. This is an open-access article distributed under the terms of the Creative Commons Attribution Non-Commercial License, which permits unrestricted non-commercial use, distribution, and reproduction in any medium, provided the original work is properly cited.

\section{ABSTRACT}

Background: To analyse gynecological and reproductive morbidities associated with unicornuate uterus with noncommunicating rudimentary horn.

Methods: This is a retrospective study of 20 cases of unicornuate uterus with noncommunicating rudimentary horn found on laparotomy in a duration of 5 years (Oct 2011-Oct 2016).

Results: Out of 20 patients, two teenagers presented with dysmenorrhoea and pain abdomen and had haematometra in the noncommunicating rudimentary horn which was excised. Eight had pregnancy in the noncommunicating rudimentary horn of which all presented after rupture and five were admitted in a state of shock. Ten patients had pregnancy in the hemiuterus with complications inherent to the condition.

Conclusions: Unicornuate uterus with noncommunicating rudimentary horn is associated with poorest outcomes among all uterine anomalies and a high index of suspicion is needed to diagnose this condition and thus to save the woman from catastrophic complications.

Keywords: Mullerian, Rudimentary, Rupture, Unicornuate

\section{INTRODUCTION}

Uterine malformations are the results of abnormal mullerian duct development-fusion, canalization and septal defects. Unicornuate uterus with a rudimentary horn is one such anomaly of uterus occurring due to fusion defects. It belongs to class-II mullerian anomalies according to classification by American fertility society. ${ }^{1}$

This malformation is rare and it can be associated with many complications throughout a woman's reproductive life beginning from menarche when hormonal stimulation may gradually activate the endometrium of the rudimentary horn. The resulting obstruction of the menstrual flow may cause hematometra, leading to endometriosis and infertility. Pregnancy in non- communicating rudimentary horn is a rare form of ectopic gestation and its incidence is between 1/100,000 to $1 / 140,000$ pregnancies. ${ }^{2,3}$

Conception in the rudimentary horn is very rare, and occurs either from small communication with uterine cavity or by trans-peritoneal migration of the sperm from contralateral side. $^{4}$ Diagnosis may be suspected by clinical examination-1) Bimanual palpation of a mass extending outside the uterine angle (Baart's de la Faille's sign); 2) displacement of the fundus to the contralateral side with rotation of the uterus and elevation of the affected horn (Ruge Simone syndrome); and 3) deviation of uterus to one side with an adnexal mass in pregnancy may indicate the presence of rudimentary horn. ${ }^{5}$ Hysterosalpingography, ultrasonography and magnetic 
resonance imaging may be useful in diagnosis of unicornuate uterus. HSG shows a deviated 'bananashaped' uterus with single fallopian tube. Trans-vaginal sonogrophy may show a small, well-formed elliptical uterus with single cornu deviated to one side. 3-D imaging and MRI may give a classic banana picture. Renal anomalies are detected in $40 \%$ of cases. Variable thickness of rudimentary horn musculature, dysfunctional endometrium and poor distensibility of the myometrium lead to rupture of the rudimentary horn. This complication is usually seen in the $2^{\text {nd }}$ trimester and can be a life-threatening condition for the mother resulting from hemoperitoneum and hemorrhagic shock. It is difficult to diagnose preoperatively and in the literature, only $5 \%$ of rudimentary horn pregnancies were diagnosed preoperatively and the remaining were found unexpectedly at laparotomy. If the pregnancy occurs in the semi-uterus of this malformation, it is associated with increased incidence of abortion, preterm labor and malpresentations. These patients also have high incidence of cesarean deliveries. ${ }^{6,7}$

With this background, a study was conducted where all cases of unicornuate uterus with rudimentary horn found on laparotomy were analysed to know their gynecological and obstetric implications.

\section{METHODS}

This is a study of 20 cases diagnosed at laparotomy at a tertiary care teaching hospital over a period of 5 years from Oct 2011-Oct 2016. which were retrospectively analyzed. These patients were divided into 2 groups: group-1 $(n=2)$ consisted of patients who presented with gynaecological complaints and in whom the condition was diagnosed at laparotomy. Group-2 $(n=18)$ consisted of gravid patients. Group-2a $(n=8)$ consisted of pregnancy in rudimentary horn of uterus group- $2 b(n=10)$ consisted of patients who had pregnancy in the semi uterus (normal horn) and the rudimentary horn happened to be an incidental finding during LSCS for some obstetric indication.

\section{RESULTS}

Group 1-the age of the two patients in this group was 18 and 13 years respectively. The first patients were referred with complain of severe pain abdomen from a peripheral hospital and USG done there showed uterine anomaly? double uterus. CT Scan done at our centre conformed the diagnosis and showed blood clots in one horn of uterus. Laparotomy was done which showed the rudimentary horn with haematometra. It was a non-communicating horn with a fibromuscular band of fusion with the other half of uterus. Resection of the rudimentary horn was done.

Another case was that of a 13 years old girl who had attained menarche 2 years back and had undergone Appendicectomy 1 year back at a peripheral hospital but the pain of right iliac fossa (for which appendicectomy was done) worsened. USG also did not point towards the unexpected cause of lingering pain. Diagnostic laparoscopy gave the diagnosis of rudimentary noncommunicating horn of uterus which was resected and was found to be having haematometra of about 75 $\mathrm{ml}$. In both cases the non-communicating rudimentary horn was of the right side.

Table 1: Pregnancy outcome in rudimentary horn pregnancy and its characteristics.

\begin{tabular}{|c|c|c|c|c|c|}
\hline $\begin{array}{l}\text { Age } \\
\text { (year) }\end{array}$ & $\begin{array}{l}\text { Obstetric } \\
\text { history }\end{array}$ & $\begin{array}{l}\text { Duration } \\
\text { of } \\
\text { gestation }\end{array}$ & Clinical Diagnosis & $\begin{array}{l}\text { Preoperative Diagnosis } \\
\text { (USG+Clinical) }\end{array}$ & $\begin{array}{l}\text { Location of } \\
\text { rudimentary } \\
\text { horn }\end{array}$ \\
\hline 27 & $\mathrm{G}_{2} \mathrm{P}_{1} \mathrm{~L}_{1}$ & 12 & $\begin{array}{l}\text { Pain abdomen USG } \\
\text { showed ectopic pregnancy } \\
\text { with haemo-peritonium }\end{array}$ & Ectopic pregnancy & Right side \\
\hline 23 & Primi & 26 & Pain in Abdomen, Shock & Rudimentary horn pregnancy & Right side \\
\hline 28 & $\mathrm{G}_{2} \mathrm{P}_{1} \mathrm{~L}_{1}$ & 27 & $\begin{array}{l}\text { Vomiting, diarrhea, pain } \\
\text { abdomen shock, history of } \\
\text { fall }\end{array}$ & ? Rupture uterus? Abruption & Right side \\
\hline 24 & Primi & 24 & Pain abdomen, shock & $\begin{array}{l}\text { Rupture of Rudimentary horn } \\
\text { pregnancy }\end{array}$ & Right \\
\hline 22 & $\mathrm{G}_{3} \mathrm{P}_{1} \mathrm{~L}_{1} \mathrm{~A}_{1}$ & 16 & $\begin{array}{l}\text { Pain abdomen, secondary } \\
\text { infertility }\end{array}$ & Rupture of cornual pregnancy & Left \\
\hline 32 & $\begin{array}{l}\text { G3P2L2 with } \\
\text { previous } \\
\text { LCSC }\end{array}$ & 17 & Pain abdomen, shock & Rupture uterus/scar pregnancy & Left \\
\hline 30 & $\mathrm{G} 2 \mathrm{~A} 1$ & 22 & $\begin{array}{l}\text { Vaginal bleeding, pain } \\
\text { abdomen }\end{array}$ & Rudimentary horn pregnancy & Right \\
\hline 29 & $\mathrm{G}_{2} \mathrm{P}_{1} \mathrm{~L}_{1}$ & 28 & Pain abdomen, shock & Rudimentary horn pregnancy & Right \\
\hline
\end{tabular}




\section{Case 2 a}

8 patients had pregnancy in the non-communicating rudimentary horn, the data of these patients is given in table 1 . One patient presented in the first trimester and 7 patients in the 2nd trimester. Pain and shock were the main presenting complain with varying degree of pallor. Preoperative diagnosis of rudimentary horn pregnancy was suspected in two cases only and in the remaining, the diagnosis was made at laparotomy. The malformation was on the right side in 6 cases and left side in two. All women underwent excision of the rudimentary horn with ipsilateral salpingoopherectomy.

\section{Case 2 b}

We witnessed non-communication rudimentary horn in 10 cases as incidentaloma during LSCS which was mostly done formal presentation and in coordinate uterine actions.

In 4 of the above cases-renal anomalies in the form of pelvic kidney and aberrant fused renal mass was seen in USG.

Table 2: Pregnancy outcome in unicornuate uterus (hemiuterus).

\begin{tabular}{|c|c|c|}
\hline Pregnancy outcome & $\begin{array}{l}\text { No. of } \\
\text { pregnancies } n=10\end{array}$ & $\%$ \\
\hline $\begin{array}{l}\text { Abortion (previous } \\
\text { pregnancy) }\end{array}$ & 2 & 20 \\
\hline Cerclage required & 3 & 30 \\
\hline Preterm & 2 & 20 \\
\hline Term & 5 & 50 \\
\hline Breech & 4 & 40 \\
\hline Transverse lie & 1 & 10 \\
\hline IUGR & 2 & 20 \\
\hline Oligohydramnios & 3 & 30 \\
\hline $\begin{array}{l}\text { Incoordinate Uterine } \\
\text { action }\end{array}$ & 2 & 20 \\
\hline IUD & 1 & 10 \\
\hline Live births & 8 & 80 \\
\hline Early neonatal death & 1 & 10 \\
\hline
\end{tabular}

\section{DISCUSSION}

It is difficult to truly estimate the incidence of these complications as the data available are in the form of case reports and surveys collected from the literature that usually has only the severe cases requiring surgery. ${ }^{7}$ High index of suspicion should be kept in teenagers presenting with dysmenorrhea. To decrease the serious complications in future, early diagnosis is of utmost importance.

The patient should be treated by excision of the rudimentary horn. If in patients presenting with infertility, hysterosalpingography shows that the uterus is deviated to one side and there is unilateral tubal block, this condition should be strongly suspected. In our analysis, hematometra was seen in two cases only.

Five of our patients presented in a state of shock due to rudimentary horn rupture. The duration of the pregnancy at the occurrence of rupture are dependent on the thickness of the myometrium. If the pregnancy grows, it usually overcomes the first trimester period uneventfully as the rudimentary horn is thicker than the fallopian tube and $80-90 \%$ of the ruptures in the second trimester. ${ }^{7,8}$ As it is associated with such catastrophe every effort should be made to diagnose it in early pregnancy but according to the literature, less than $5 \%$ of the reported cases were diagnosed preoperatively and mostly the diagnosis was made at laparotomy or laparoscopy. ${ }^{3}$

A careful pelvic examination in the $1^{\text {st }}$ trimester showing deviated uterus with palpable contra-lateral pelvic adnexa should arouse suspicion of uterine anomaly. ${ }^{9}$ Ultrasonogaphy can also pick up this anomaly with reasonable accuracy. A gestational sac surrounded by myometrium by the side of a normal empty uterus and non-communication of gestational sac with the endometrial cavity and the cervix differentiates it from pregnancy in one of the horns of a bicornuate uterus. ${ }^{6,8,10}$ MRI and CT scan are also gaining popularity for diagnosing uterine malformations. Both clinically and radiologically the diagnosis is more accurate in the early first trimester when the two horns are separate in the pelvis.

Once the diagnosis is strongly suspected these patients should be taken up for laparoscopy or laparotomy, depending upon the general condition of the patient, and the rudimentary horn should be excised along with its tube, so as to prevent future tubal ectopic pregnancy in that tube.

In present study, preoperative diagnosis was possible on clinical and sonography findings in only four out of the eight patients, and that too because of high index of suspicion as in our hospital the relative occurrence of complications arising out of rudimentary horn is higher than its occurrence in the general population for unexplained reason. In a study by Goel et al pre-operative diagnosis was suspected in 2/7 cases. $^{12}$ In our study one case was seen in $1^{\text {st }}$ trimester as ectopic pregnancy, and seven cases were seen in $2^{\text {nd }}$ trimester. The rudimentary horn should be excised whenever diagnosed. Laparotomy with resection of rudimentary horn was done in all rudimentary horn pregnancies in present study similar to study by Vani Malhotra et al. ${ }^{12}$ Indications for resection (Anne deviwold, 2006) are rupture, unilateral dysmenorrea, and haematometra. ${ }^{13}$ In all such cases, evaluation of renal system is indicated because of the high incidence of associated urological anomalies.

In present study, ten pregnancies occurred in unicornuate uterus with rudimentary horn and diagnosis was made 
incidentally at LSCS similar to studies by Vani Malhotra and Goel et al. ${ }^{12,11}$ All obstetric complications like abortion, preterm delivery, IUGR, IUD, were more compared to normal, similar to study by Goel et al. ${ }^{11}$ Rate of abortion was $20 \%$, similar to $25.8 \%$ in Goel et al and $24.3 \%$ in Reichman et al. ${ }^{11,14}$ Rate of pre-term delivery was $20 \%$ similar to $20.1 \%$ in Reichman et al. ${ }^{14} 10 \%$ had intrauterine fetal demise compared to $3.8 \%$ in Reichman et al. ${ }^{14}$ Pregnancy outcome in present study was poor overall. However, rate of term delivery was $50 \%$, compared to $32.25 \%$ in Goel et al may be because of good antenatal care overall. Live birth rate was $80 \% .^{11}$

\section{CONCLUSION}

Unicornuate uterus with noncommunicating rudimentary horn is associated with poorest outcomes among all uterine anomalies and a high index of suspicion is needed to diagnose this condition and thus to save the woman from catastrophic complications.

\section{ACKNOWLEDGMENTS}

Authors would like to thank the patients born with this rare anomaly who were unfortunate enough to have these complications but provided an impetus for this study.

Funding: No funding sources

Conflict of interest: None declared

Ethical approval: The study was approved by the Institutional Ethics Committee

\section{REFERENCES}

1. Hoffman BL, Schaffer JO. chapter 18, Anatomic disorders, Williams gynaecology, $2^{\text {nd }}$ edition; 2012:497-8.

2. Johansen K. Pregnancy in a rudimentary horn: Two case reports. Obstet Gynecol. 1969;34:805-8.

3. O'Leary JL, O'Leary JA. Rudimentary horn pregnancy. Obstet Gynecol. 1963;22:371-5.

4. Elagwany AS, Elgamal HH, Abdeldayem TM. Ruptured ectopic pregnancy in non-communicating right rudimentary horn: a case report. Apollo Medicine. 2016;13(4):249-52.

5. Bhattacharya TK, Sengupta P. Rudimentary horn pregnancy. Med J Armed Forces India. 2005;61:377.

6. Heinomen PK, Saarikoski S, Pystynen P. Reproductive performance of women with uterine anomalies: An evaluation of 182 cases. Acta Obstet Gynecol Scand. 1982;61:157-62.

7. Heinonen PK. Clinical implications of the unicornuate uterus with rudimentary horn. Int $\mathrm{J}$ Gynecol Obstet. 1983;21:145-50.

8. Tsuda H, Fujinov, Umesaki N. Preoperative diagnosis of a rudimentary uterine horn. Eur J obstet Gynecol Reprod Bio. 1994;56:143-5.

9. Liu MM. Unicornuate uterus with rudimentary horn: Int J Gynecol Obstet. 1994;44:149-53.

10. Kriplani A, Relan S, Mittal S. Prerupture diagnosis and management of rudimentary horn pregnancy in the first trimester. Eur J Obstet Gynecol Reprod Bio. 1995;58:203-5.

11. Goel P, Aggarwal A, Devi K, Takkar N, Saha PK, Huria :Unicornuate uterus with non-communicating rudimentary horn different clinical presentations. J Obstet Gynecol India. 2005;55:155-8.

12. Malhotra V, Lakra P, Nanda S, Chauhan M. Clinical Spectrum of Un-icornuate Uterus with Noncommunicating Rudi-mentary Horn: Five-Year Analysis at a Tertiary Care Center J gynaec surgery. 2014;30(2):87-90.

13. Anne S. Deviwold, Norman phan, Adyin Arici. Anatomic factors in recurrent pregnancy loss. Se-min Reprod. Med. 2006;24(1):25-32

14. Reichman D, Laufer MR, Robinson BK. Pregnancy outcomes in unicornuate uteri: a review. Fertil Steril. 2015;103(6):1615-8.

Cite this article as: Kamal S, Roy P. A study of complications in case of unicornuate uterus with rudimentary horn. Int J Reprod Contracept Obstet Gynecol 2017;6:2607-10. 